\title{
Pupils' Opinions on an Educational Virtual Reality Game in Terms of Flow Experience
}

https://doi.org/10.3991/ijet.v14i15.10576

\author{
Emrah Akman ( $\left.{ }^{\varpi}\right)$, Recep Çakır \\ Amasya University, Amasya, Turkey \\ emrahakmandoutlook.com.tr
}

\begin{abstract}
The purpose of the study is; to evaluate a game developed by using virtual reality technology in the teaching of fractions which is one of the most difficult topics in the fourth-grade mathematics curriculum, according to the opinions of pupils. An educational virtual reality game (Keşfet Kurtul) was developed for the study. During the development of the game, the ideas of experts were utilized and flow theory was taken into account. The educational virtual reality game was developed in the light of the flow theory. The research was carried out in a school in Samsun with 4 th grade pupils. The game was evaluated by the pupils in terms of overall evaluation, challenge-skills balance, concentration on the task, clear goals, sense of control, action-awareness merging, loss of self-consciousness, transformation of time, unambiguous feedback and autotelic experience. As a result, the educational virtual reality game Keşfet Kurtul is a digital learning environment that pupils enjoyed a lot. It has been determined that all tasks except the "radio" task, and in general the game itself, provide flow experience. It is proposed to redesign just one task of the game in terms of challenge-skills balance and clear goals. It's suggested that in experimental studies, different variables can be examined.
\end{abstract}

Keywords - Virtual reality, digital educational games, fractions, primary school education, educational technology

\section{$1 \quad$ Introduction}

The rapid development of technology provides convenience to many people and the use of this technology has been expanding quite rapidly in recent years. In education, which is one of these areas, the rate of technology usage is also increasing. Many researchers are studying new technologies that can be used in the educational environment. Therefore, the educational dimension of virtual environments is also gaining importance.

\subsection{Virtual environment}

Virtual environments, with physical structures and backgrounds, create a feeling of being in the desired mental environment. Virtual environments motivate students to 
discover more and make students become self-confident, exploratory individuals [34]. Virtual reality (VR) brings impressive experiences to the user in a virtual environment $[18,36]$. With the development of low-cost computer graphics, virtual reality, which is rapidly becoming popular as an educational tool $[9,37]$, is one of the most powerful technologies that has the potential to be actively used in education $[8,35]$. VR teaching environments provide experiences that can positively influence teaching achievements $[17,35]$. Multimedia, such as VR, can be applied in units of mathematics to increase the academic achievement of students [13]. VR contributes to learning by providing opportunities to discover and experience unattainable situations such as distance, time, price and security [8]. VR allows students to learn at their own pace and supports the constructivist paradigm [4]. According to these studies, it would be beneficial to use VR in education. However, VR applications to be used in education need to have certain properties. Çavaş, Çavaş and Taşkın [12] grouped and defined the properties of VR environments used in education. According to this definition, the properties that VR environments should have are;

- Interaction: The student must be able to interact with the object in the VR environment and to engage with the objects.

- Attracting the attention of the learners: The students are generally focused on the subject in VR environments.

- Story Flexibility: In the context of VR, subjects must have a narrative feature.

- Experiential: Students should be able to gain experience in the activities they perform through VR environments.

- Attention to the senses: The systems should provide persistence by stimulating as many emotions as possible for the students.

Tan and Waugh [33] stated that the visualization exercises with VR helped to increase understanding whilst stimulating interest and engagement. Because of this VR serves to bring about significant improvements in achievement scores [33]. VR applications can be used as a tool to facilitate teaching and to enhance the achievement of students [2].

In the virtual environment, there are points to be aware of while preparing the scenario of educational games. The scenario must be based on true stories or as close to one of them as possible [1]. In addition, details should be planned as the student progresses through the scenario [5]. The key points to note in the scenario for software are as followings [6];

- A realistic / convincing scenario

- Taking into account all possible situations that can occur, placing these possible situations in the scenario

- Providing the details that the learner will need in the decision-making process

- Use of appropriate visualizations

- Feedbacks

- Have appropriate examples for situations where comparisons are used 
In the design of the tasks involved in the contents of the scenario, the following must be observed [30]:

- Targets must be clear and understandable

- Tasks should be presented in a manner appropriate to the nature of the story

- It should include goals that can be adopted by the students and thus motivate the student

- Tasks should include different activities

- The achievement of the tasks must depend on the targeted skills

- Students should think that they can do the next task at the end of each task

- There must be alternative ways to achieve the goal

- If the student has a problem about completing the task, $\mathrm{s} / \mathrm{he}$ should be able to return to the previous stage or try a different task

\subsection{Theoretical framework}

In addition to scenario, tasks and virtual environment design, it is also important that educational digital games provide a flow experience. The flow experience is the mental state in which the person is involved in the action [10]. Flow experience is a positive and beneficial experience for the student because the student has the ability to develop his or her own skills and abilities as well as the action $\mathrm{s} / \mathrm{he}$ is doing [10]. Csikszentmihalyi's Flow Theory consist of nine elements:

- Challenge - skills balance

- Action - awareness merging

- Clear goals

- Unambiguous feedback

- Concentration on the task

- Sense of control

- Loss of self-consciousness

- Transformation of time

- Autotelic experience.

When designing a VR game, it is important that the flow experience, scenarios, tasks and virtual environment properties meet the criteria. With a VR game that meets the criteria, it would be sensible to use it in subjects that pupils have a learning disadvantage. Fractions, which is one of the most difficult subjects in primary school, is suitable for using educational VR games.

\subsection{Fractions}

Fraction is a concept that indicates the relationship between a whole and a piece of it [28]. When we look at the fourth-grade mathematics program in primary school, fractions account for about $20 \%$ of the mathematics program [19]. Fractions is one of the most difficult mathematics topics for both teachers and pupils [27, 7, 21]. Pupils 
learn the operations with fractions every year, but soon forget them. The reasons for the pupils' inability to permanently learn fractions and operations with fractions are that they try to memorize formulas and algorithms instead of fractions and think of numerators and denominators of fractions as two distinct integers [32]. One of the most important reasons why the subject of fractions cannot be learned is that the child tries to apply the learned rules about exact numbers to operations with fractions [31]. It is stated that difficulties in learning fractions, are seen at every class level based on the concept of fractions [27]. It seems that pupils have difficulties in learning subjects like operations with fractions, understanding of the concept of fractions, sorting in fractions and showing fractions on the number line.

Research has shown that primary school pupils have difficulty in expressing pieces as fractions [22]. It has been found that pupils have difficulty in understanding that they express a single fraction as a whole. It has been seen that the pupils interpret the numerator and denominator as two different numbers with different values. Therefore, it is determined that they have difficulty in operations with fractions [14]. Pupils add the numerator and denominator in the same fraction and write the result as a natural number in the adding operations with fractions [29]. Similarly, while performing subtraction, it is known that they are substracting small numbers from large numbers and reach the wrong result [28]. Researches show that pupils order fractions like natural numbers [14]. It was determined that they cannot write the appropriate fraction to the points specified on the number line and they were not able to divide the whole into parts $[29,28]$. The elimination of these learning difficulties that pupils are experiencing about fractions has a great prospect in terms of the mathematical topics they will learn in the future. It is stated that these learning difficulties arise in situations especially where visualization has not been done [27]. Under these circumstances, the importance of visualization in the subject of fractions arises. It is effective and useful for pupils to encounter different problem situations in order to understand the fractions in different situations [14]. The use of some models makes it easier to learn the concept of fractions. This is useful in operations with fractions for pupils [7]. If fractions and the concepts are well understood and the operations with fractions can be done meaningfully by the pupils in the primary school, the pupils will gain knowledge which they can use in their future mathematics learning, other lessons and daily life [3]. In this case, it can be said that understanding fractions in a meaningful way contributes not only to the success of mathematics but also to the success of the pupil in other fields.

The purpose of this research is to evaluate the game developed by using VR technology in the teaching of fractions which is one of the topics with the most learning difficulties among fourth-grade mathematics subjects, according to the opinions of pupils. For this purpose, the research question was set as "How do pupils interpret the experience they have with the educational virtual reality game according to the flow theory?". 


\section{Materials and Methods}

\subsection{Participants}

In the study, purposive sampling was applied to select pupils to gain insight and indepth understanding about their perceptions of the game. The educational VR game was used in two $4^{\text {th }}$ grade classes in a private school in Samsun, Turkey. These classes, which have teachers with similar educational experience, have taught the same content in lessons. Semi-structured interviews were held with five participant pupils in these classes. Attention was paid to the pupils' willingness to have an interview. Explanations have been made to the pupils about the confidentiality of their interview records. The interviewed pupils were nine years old which was the average age of the class.

\subsection{The educational virtual reality game (Keşfet Kurtul)}

Keşfet Kurtul (meaning Explore to Survive) was the name given to the educational VR game used in the study. During the development of the game, the ideas of experts in the field of games and mathematics were utilized. In addition, opinions were received from mathematics and primary school teachers.

Scenario: The pupil gets on a cargo plane to the Space Agency, then the plane takes off. The plane starts to fall and someone places the pupil in safe-boxes with important items. These safe-boxes are opened with passwords. Then the pupil finds him/herself in a safe-box. The pupil needs to solve the password of the box by responding correctly to the 3 questions on the subject of fractions. After unlocking the box, the box opens and the pupil finds him/herself on an island. There are other boxes on the island. The pupil opens these boxes one by one and collects materials from each box. These materials will be used for completion of further tasks. Another island is nearby. The wreckage of the plane stands on that island. One of the tasks is go to that island where the plane is. A raft has to be built to cross that island. Another task is building a tent to stay at night. The pupil completes tasks like this, one by one. In the final task, the pupil draws the attention of rescue teams and succeeds in getting rid of the island. In every task of the game, the pupil is doing activities about fractions. If the pupil fails in these tasks, feedback is given. 


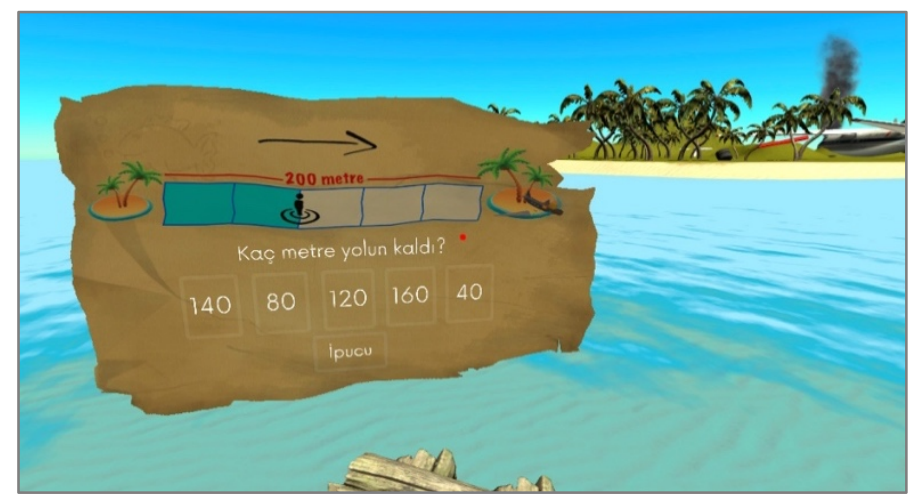

Fig. 1. An example question: "How many meters to the opposite island?"

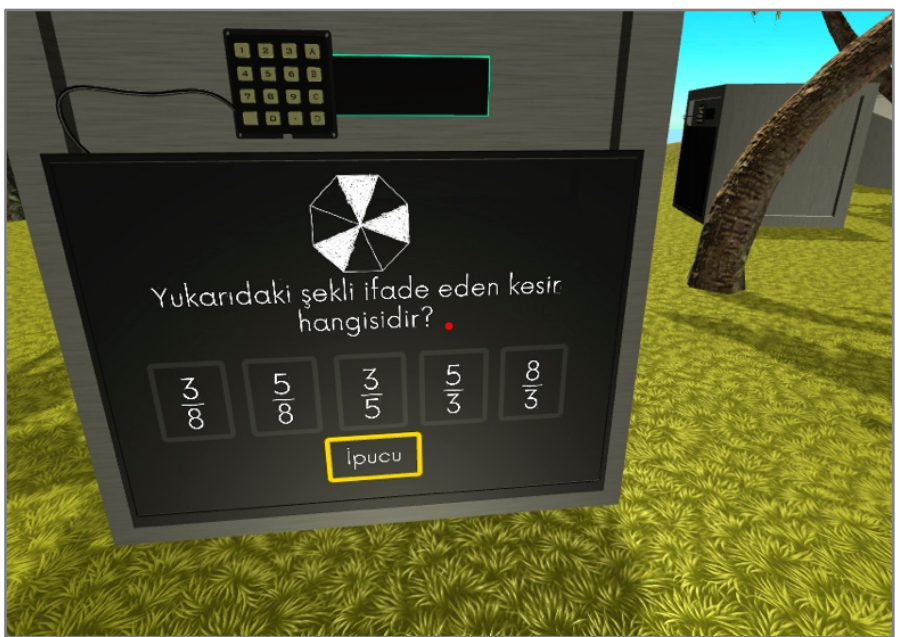

Fig. 2. Another example question: "What fraction of the figure shown above?"

User Interface: On the opening menu of the game, the scene which is the starting point of the scenario is used. This scene was designed to include walking for a while to start the game, so that the user is familiar with the movements and learns the navigation menu before the game starts. The navigation in the game is designed in a simple and understandable way and supported with icons.

Orientation and Navigation: The navigation is visible when the user looks down. There are walk, stop, main menu and restart buttons in the navigation (Figure $3 \&$ Figure 4). The gaze-based movement control technique is used in the game. This technique allows the player to move in the direction being looked at. Some of the buttons are hidden in some scenes if not needed. Sparkles were placed on the targets to give clues to the pupils (Figure 5). 
Paper-Pupils' Opinions on an Educational Virtual Reality Game in Terms of Flow Experience
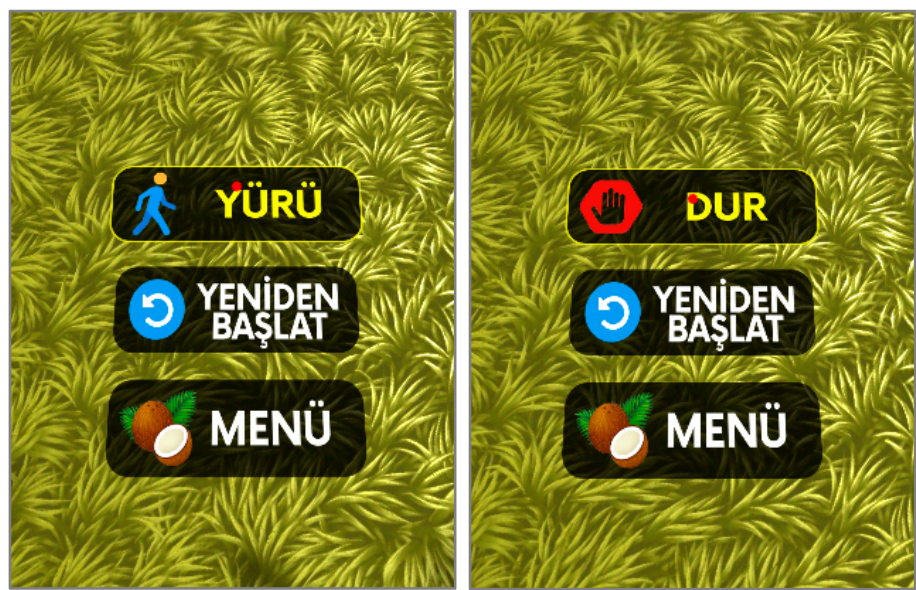

Fig. 3. Walk (Yürü), Stop (Dur), Restart (Yeniden Başlat) and Main Menu (Menü) buttons in the navigation

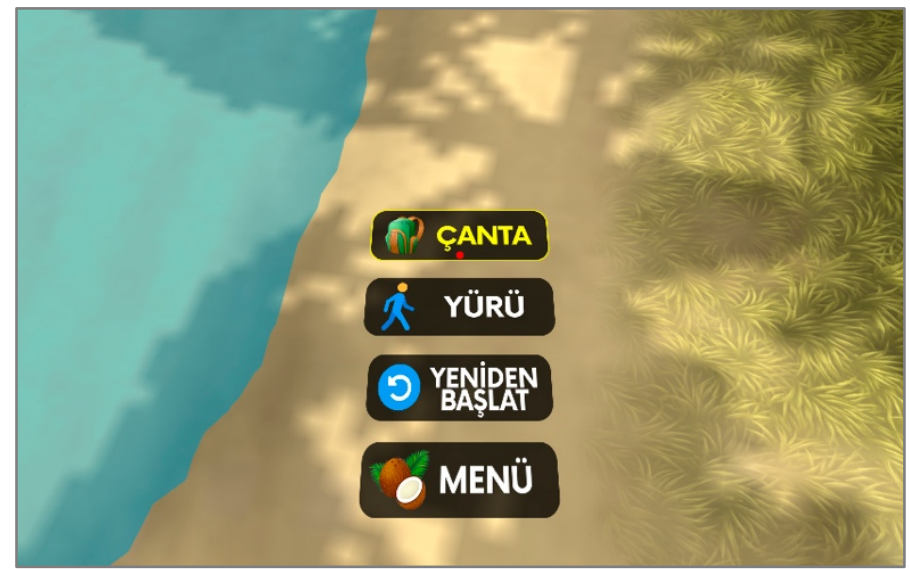

Fig. 4. Backpack (Çanta) as an inventory button in the navigation 

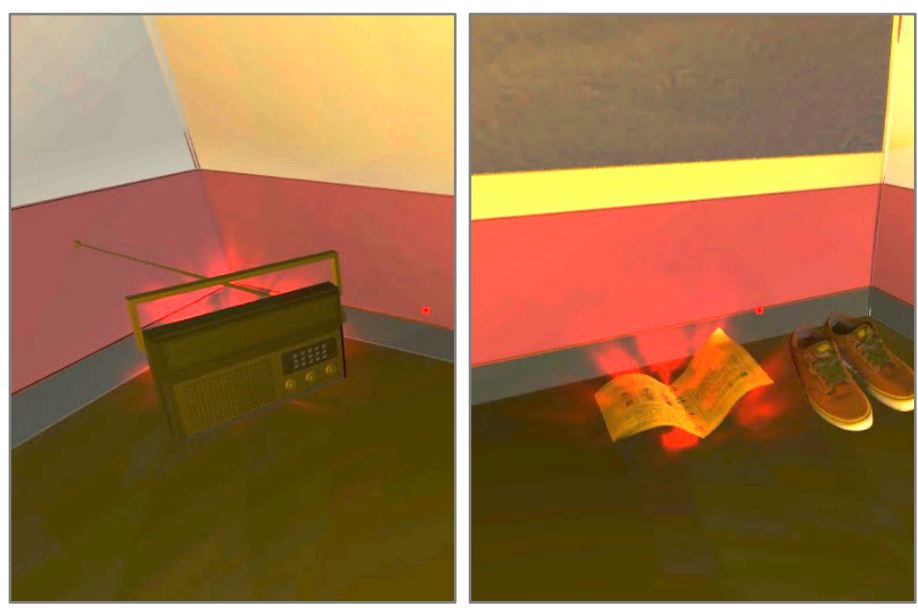

Fig. 5. Sparkles as a guiding element

Audio Help System : In order to help the player, they are guided by the voice of the mysterious person in the script. These orientations help the player to focus on the goals.

Tools: There are tools that the player needs to use in the game. Some basic objects can be used in the game to reach the goals. A backpack to collect materials to use later, footwear to move faster, a match box to light something, a rope to use in building a boat, a tent to stay at night are basic tools of the game (Figure 6).

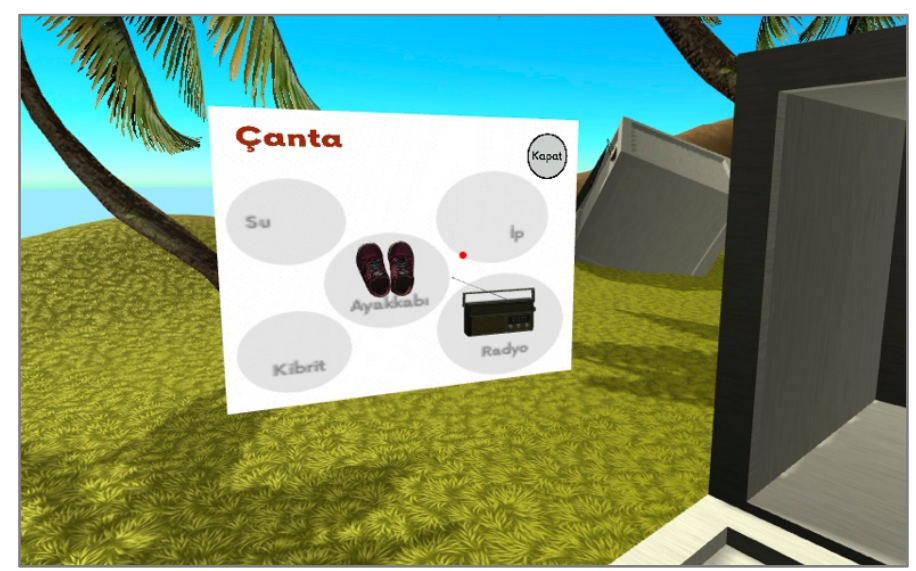

Fig. 6. Figure 6. Backpack (çanta) as an inventory panel

Hardware and Software Setup: In the process of running the game, a smart phone (android), VR headset (cardboard) and headphones are used (Figure 7). It has been noted that the device used as a smartphone is in a level that meets the requirements of the game and is dimensionally compatible with the VR headsets. In terms of portability and applicability for use in a classroom environment, VR headsets, known 
as cardboard, were preferred. Since these headsets work by placing a smart phone inside, they can be used in portable form. Headphones are used to transfer ambient sounds to the user.

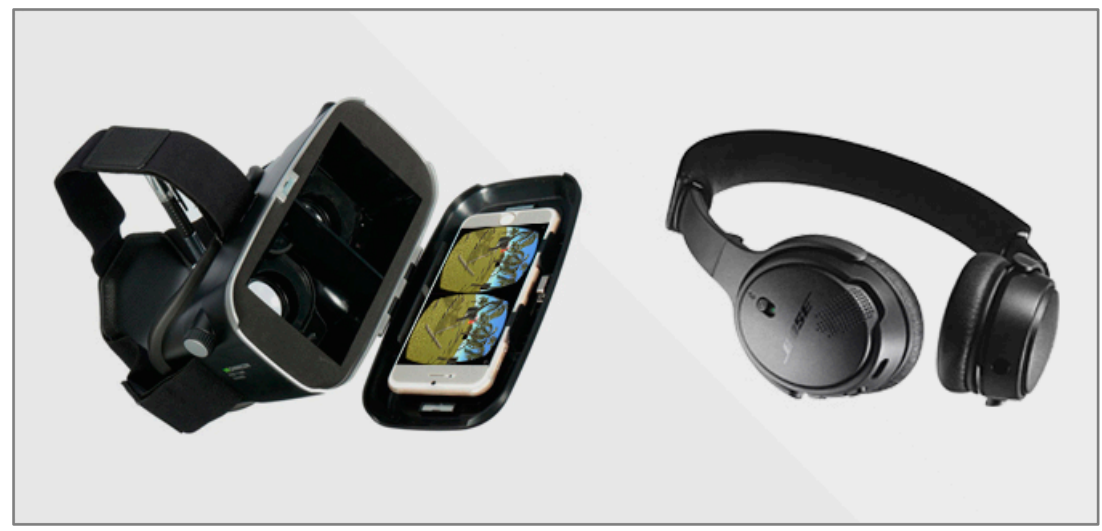

Fig. 7. The VR headset used in the classroom: A cardboard, a smart phone and a headphone

The game is designed to work on the android operating system. During the development phase, Unity 3D software was used with the Unity Personal free license, and because of resource richness, the $\mathrm{C} \#$ coding language was preferred. The development of the game was done by the researcher. The 3D models and music included in the game were selected from free-to-use sources.

\subsection{Implementation}

This study was carried out in two 4th grade classrooms in a primary school in Samsun, Turkey. The VR game was introduced to pupils as part of the fractions unit. All of the pupils experienced VR for the first time. All received five minutes introduction into the system consisting of an explanation of how to use VR headsets and how to move in the game. The pupils took five hours of mathematics lessons per week and before playing Keşfet Kurtul (the VR game) the pupils had been involved in a fourhour lesson on fractions. The pupils played Keşfet Kurtul in the fifth maths hour of the week. The unit of fractions lasted four weeks and pupils played a chapter of the game every week.

\subsection{Data collection}

In this qualitative study, the major data gathering method involves primarily indepth interviews with participants. Interviews were held with participants after the unit of fractions was over. Our interviews with five pupils using Keşfet Kurtul lasted anywhere from 15 to $30 \mathrm{~min}$, included a variety of set questions and probes that helped pupils describe their experiences in using the Keşfet Kurtul educational VR game. When the interview questions were prepared, flow theory was taken as the 
basis and opinions were obtained from two field experts about the interview questions. After the interview questions were prepared, they were tested to ensure reliability.

\subsection{Data analysis}

Data analysis proceeds through the methodology of reduction, the analysis of specific statements and themes, and a search for all possible meanings [11]. Interviews were audio-recorded and the records transcribed by the researcher. The recordings were analyzed by using qualitative content analysis. Codes, categories and themes were determined together with an expert. The terms of credibility, transferability and dependability determine the trustworthiness of the study [20]. Evidence for the validity and reliability of the study include; expert reviews, detailed descriptions, purposive sampling and audit trail.

\section{$3 \quad$ Results}

In order to determine the evidence of flow experience in the educational VR game, it has been evaluated in terms of challenge - skills balance, action - awareness merging, clear goals, unambiguous feedback, concentration on the task, sense of control, loss of self-consciousness, transformation of time and autotelic experience. The results also include the overall evaluation of the game.

\subsection{Overall evaluation}

Pupils were asked about the general ideas about the game and how they felt about it. Positive responses towards the VR game were received in the "What do you think about the game?" question directed to the pupils. It was found that all of the pupils shared a consistent point of view: that is, they considered the VR game as "a beautiful game", "enjoyable" and "very good".

It's a beautiful game. Everything seems so realistic.

"How did you feel during the game?" question asked in order to reveal what pupils felt while playing. It was seen that pupils were excited and entertained in the game.

"I was excited when I first played the game because I was going to play a game with headsets for the first time. I also wondered about the game. Finally, I realized that it was a good game."

The pupils said they were excited about using the VR headsets for the first time. They continued to tell their feelings about the game.

"Strange. For the first time in my life I was playing with virtual reality headsets. It was nice. It was fun, it was so nice to open the box by solving the questions. It's more fun with the questions."

The realism of the game is one of the basic elements that allows the player to connect to the game. For this reason, pupils were asked questions about the realism of the 
game. In these questions, concepts of realism [23], interaction, concentration [10], control $[15,16]$ and immersion/timelessness $[10]$ are included.

There are factors that affect the quality of the game, such as player skills [15], level of difficulty of the game [25], pupils' focus on the tasks, and understandability of the tasks [10, 23]. Pupils were asked about challenge-skills balance, player skills, concentration and clarity of tasks.

\subsection{Concentration on the task}

The pupils were asked the question "Did you focus on the tasks?" and the pupils said "yes". A sample answer is as follows:

"I was not distracted. I could focus on the tasks."

The pupils were asked the question "Were there any distractions in the game? If yes, what were those distractions?" and pupils consistently used expressions that mean "no".

In another question, the pupils were asked "Have you interacted with the objects in the game?" and they said "yes". When a pupil responded to this question, he used an expression about the reality of the game. He said "It felt as if it were real, everything has fallen away from the sky. Some things have disappeared.". In this answer, the pupil actually talks about the realism of the story.

\subsection{Sense of control}

Players should feel a sense of control over movement and game controls [23]. The question "Could you control things in the game?" was asked to reveal the control feelings pupils had when playing. A sample answer is as follows:

"I could do what I wanted to do in the game."

According to the responses, the pupils had a sense of control when playing the VR game.

\subsection{Transformation of time}

The element of flow often results in loss of sense of time [10]. With the question "Did you notice how the time passed?" asked to the pupils, information about the sense of time of the pupils was obtained. To emphasize that the time passed quickly, a pupil said, "Fridays were very quick. I did not understand how a lesson finished.". Another participant pupil said that "I played this game for a very short time, but it took about 15 minutes.". These responses show that the pupils' sense of time had altered.

\subsection{Challenge - Skills balance}

Pupils were asked the question "What do you think about the tasks in the game?". 
"There was tasks of fireworks and a boat... There was a radio task... The task of opening the boxes. Question solving. It was so beautiful."

"We threw fireworks. We set the frequency to turn on the radio. It was fun."

"It's good for the game to be hard, it's not enjoyable when it's too easy. It was not too hard and it wasn't too easy."

Pupils did not find the tasks too easy or too difficult. Whether the questions are too difficult or too easy is important for the flow experience [23]. When the overall difficulty level in the game was asked with the question "How was the level of difficulty?", it was determined that the pupils thought that the difficulty level of the game was normal. The pupils did not make any statement about the need to be helped to play the game. This shows that the game is suitable for the skills of players.

\subsection{Clear goals}

The question "Did you completely understand the tasks and focus on the tasks?" was asked to the pupils in order to get information about the clarity of the tasks and pupils' concentration on the game.

"Sometimes I didn't understand what to do, but this wasn't often. I did not fully understand the task of tuning the radio frequency. I understood all the other tasks."

Pupils were asked about the question "Did you think you could not do the tasks?", and detailed information about the difficulty of the tasks was obtained.

"Some tasks were difficult. It's hard for me when I do not understand. For example, the radio task was difficult. I did not understand it, so I struggled."

"There were moments when I had difficulty. The radio task, for example, was hard. I had a little difficulty on the radio. There was nothing else. I just struggled to do the radio task, that's all."

Pupils said that they had difficulty understanding the "radio" task. The "radio" task should be made clearer by making arrangements to achieve flow experience $[10,23]$.

\subsection{Action-Awareness merging}

In interviews with the pupils, it was seen that there were answers about the actionawareness merging dimension of flow theory. Pupils' responses include expressions such as "I fell into water" and "I'm there now". These explanations show that the pupils became absorbed in their activity.

\subsection{Loss of self-consciousness}

It was found that pupils used expressions which were coded as self-consciousness. Some expressions of pupils were as follows:

"It felt like I was real."

"I felt like I was seriously lost on an island."

"I was in the water once. The voice said: 'You have no chance to get there in the water.' I mean, it was really realistic." 
When the answers were evaluated, it is seen that the loss of self-consciousness dimension is experienced while the game is being played.

\subsection{Unambiguous feedback}

It is important to give feedback on the necessary situation in a game [10]. Pupils were asked questions about feedback and orientations. It was seen that directions and feedback were positive for the pupils. The question "How were the orientations in the game?" was asked to pupils. The expressions "The man tells me where to go. I can say that he was good." and "There is a man talking in the background... That was good." indicates that the pupils were satisfied with the voice feedbacks (vocalization). It seems that the markers are functioning with the "There is a red light. I went to see if there's something there." citation of the pupil.

The pupils were asked "How realistic was the environment in the game?" and the answers were taken as follows:

"I went into the sea. The man said: 'You cannot swim to the other island.' I mean, it was real. For example, I went to the cow. The man said: 'You had better not disturb the cow.",

"What I find realistic is the questions follow from what we worked on earlier in the week. What I do not find realistic is the voice of the man in the background."

In the first sentence the pupil stated that giving voice feedback gives realism to the playing environment. In the second sentence, the other pupil admitted that the voice feedback negatively affects the reality of the game, and he / she stated that it was realistic to ask questions about the topics they had learned that week. In this case, the voice feedback should belong to another character or object in the environment.

\subsection{Autotelic experience}

Pupils' desire to do the activity again is interpreted as a sign of autotelic experience. When the interviews with the pupils are examined, it is seen that the pupils are very willing to play the educational virtual reality game again. Some of the expressions used by the pupils are as follows:

"How can I play the next part of the game?"

"The game was so much fun. Can we play again, please?"

The pupils' willingness to play the game again is proof of the autotelic experience, but it also shows that the game is fun to play.

When pupil responses are evaluated considering flow experience, positive responses are seen in the overall evaluation, concentration on the task, sense of control, action-awareness merging, loss of self-consciousness, transformation of time, unambiguous feedback and autotelic experience. However, it is seen that pupils have negative answers in the clear goals dimension. In the challenge-skills balance dimension, it is seen that the game has moderate difficulty. The responses in clear goals and challenge-skills balance dimensions relate only to one task, not to all tasks. 


\section{Discussion}

This study was carried out to evaluate pupils' experiences of flow in a virtual reality game by examining their comments. When the VR game was developed, properties of VR environments used in education [12], key points in the scenario for software [6], criteria for tasks [30] and flow theory elements [10] were taken into consideration.

The research question is "How do pupils interpret the experience they have with the educational virtual reality game according to the Flow Theory?". The developed educational VR game "Keşfet Kurtul" is satisfactory when it is evaluated by the pupils in terms of the overall evaluation, challenge-skills balance, concentration on the task, clear goals, sense of control, action-awareness merging, loss of self-consciousness, transformation of time, unambiguous feedback and autotelic experience. In the dimensions of clear goals and challenge-skills balance, it seems that they only have difficulty in the "radio" task. Pupils are challenged in that tasks. This is because the tasks were not clear enough. By redesigning this "radio" task, an appropriate learning environment can be provided for the pupils as well as for other tasks of the game. In general, the educational VR game Keşfet Kurtul is a digital learning environment that pupils are quite happy to play. It has been determined that all tasks except the "Radio" task, and in general the game itself, provide flow experience. In addition, in the overall evaluation, it was found that the pupils enjoyed the game very much.

The results obtained in some studies have included positive findings about the use of VR in education. Lau and Lee [24] stated that the pupils enjoyed their learning experiences during the lesson in the simulated VR. Chen [8] has shown that pupils who play in an interactive VR environment have a better understanding of abstract concepts. Çoruk and Çakır [13] concluded that VR is a tool that can be applied in mathematics units to increase the academic achievement of pupils. In a meta-analysis study run by Merchant, Goetz, Cifuentes, Keeney-Kennicutt and Davis, it is stated that the literature presents numerous advantages of using VR-based instruction for learning [26].

VR environments are suitable for learning by the pupils' own experience. In future studies, different topics can be taught through similar scenarios and educational VR games. Keşfet Kurtul is a game that the pupils can play alone, but the game can be transformed into a multiplayer. Thus, pupils can participate in the same place on the island and interact with each other in the VR environment. In addition, the teacher can also be part of the game with their pupils. The teacher can take the place of the guides in the game. Apart from a multiplayer feature, many features can be added to the game. Experimental studies can be conducted on the effectiveness of Keşfet Kurtul. In experimental studies, different variables can be examined.

\section{Acknowledgement}

The author is very grateful to the experts who gave their opinions, and to pupils and teachers who participated in the study. In the development process of the VR 
game, the support provided by family and friends was valuable and meaningful. And finally, the author would like to thank his academic advisor for the patient guidance, encouragement and advice he has provided.

\section{Disclosure Statement}

No potential conflict of interest was reported by the authors.

\section{$7 \quad$ References}

[1] Açıkgöz, K. Ü. (2007). Aktif Öğrenme [Active Learning]. İzmir: Biliş Publishing.

[2] Aktamıs, H. \& Arııı, V. A. (2013). The effects of using virtual reality software in teaching astronomy subjects on academic achievement and retention. Mersin University Journal of the Faculty of Education, 9(2), 58-70.

[3] Alacacı, C. (2010). Öğrencilerin kesirler konusundaki kavram yanılgıları [Misconceptions of pupils about fractions]. Bingölbali, E. \& Özmantar M. F. (Ed.), Matematiksel Zorluklar ve Çözüm Önerileri [Mathematical Difficulties and Solution Suggestions]. Ankara, Turkey: PegemA Publishing.

[4] Annetta, L., Mangrum, J., Holmes, S., Collazo, K. \& Cheng M.T. (2009) Bridging realty to virtual reality: Investigating gender effect and student engagement on learning through video game play in an elementary school classroom, International Journal of Science Education, 31(8), 1091-1113. https://doi.org/10.1080/09500690801968656

[5] Arabacioğlu, T. (2012). The effect of scenario based teaching programme through different communication media on the achievement of students in information technology class. Doctoral Thesis. Adnan Menderes University Institute of Social Sciences, Aydın, Turkey.

[6] Bell, S. \& Page, R. (2003). Development of Scenario Based Learning. New Zealand: Dunmore Press.

[7] Biber, A. Ç., Tuna, A. \& Aktaş, O. (2013). Students' misconceptions of fractions and its effect on solving fractions problems. Trakya University Journal of Education. 3(2), 152162.

[8] Chen C. J. (2007). Formative research on the instructional design process of virtual reality based learning environment. In ICT: Providing choices for learners and learning. Proceedings ascilite, Singapore 2007. http://ascilite.org.au/conferences/singapore07/procs/chen.pdf

[9] Chuah, K. M., Chen, C. J., \& Teh, C.-S. (2011). Designing a desktop virtual reality-based learning environment with emotional consideration. Research ve Practice in Technology Enhanced Learning, 6(1), 25-42.

[10] Csikszentmihalyi, M. (1990). Flow: The Psychology of Optimal Experience. Harper Perennial, New York.

[11] Creswell, J. W. (1998). Qualitative inquiry and research design: Choosing among five traditions. Thousand Oaks, CA: Sage. https://doi.org/10.1086/317417

[12] Çavaş, B., Çavaş, P, H. \& Taşkın C, B. (2004). Eğitimde sanal gerçeklik [VR in education]. The Turkish Online Journal of Educational Technology - TOJET. 3(4), 110-16.

[13] Çoruk, H. \& Çakır, R. (2017). The effect of multimedia usage on academic achievement and anxiety of primary school students. Turkish Journal of Computer and Mathematics Education, 8(1), 1-27. 
[14] Ersoy, Y. \& Ardahan, H. (2003). "İlköğretim okullarında kesirlerin öğretimi II: Tanıya yönelik etkinlikler düzenleme [Teaching of fractions in primary schools II: Organizing events for diagnosis].

http://www.matder.org.tr/index.php?option=com_content\&view=article\&id=64:ilkogretim -okullarinda-kesirlerin-ogretimi-ii-taniya-yonelik-etkinlikler-duzenleme\&catid=8:mate matik-kosesi-makaleleri\&Itemid=172, Online: 02.06 .2018 . https://doi.org/10.17051/io. 2014.11721

[15] Federoff, M. (2002). Heuristics and usability guidelines for the creation and evaluation of fun in video games. Unpublished thesis, Indiana Univ., Bloomington. http://ocw.metu.edu.tr/file.php/85/ceit706 2/10/MelissaFederoff_Heuiristics.pdf. Online: 02.06 .2018 .

[16] Gee, J. P. (2004). Learning by design: Games as learning machines. Gamasutra. Online May. 1, 2018. https://gamasutra.com/view/feature/130469/learning by design games as . php

[17] Goodwin M.S., Wiltshire T., Fiore S.M. (2015) Applying research in the cognitive sciences to the design and delivery of instruction in virtual reality learning environments. In: Shumaker R., Lackey S. (eds) Virtual, Augmented and Mixed Reality. VAMR 2015. Lecture Notes in Computer Science, 9179. Springer, Cham. https://doi.org/10.1007/978-3-31921067-4 29

[18] Gopinath Bharathi, A. K. B. \& Tucker, C. S. (2015). Investigating the impact of interactive immersive virtual reality environments in enhancing task performance in online engineering design activities. 12th International Conference on Design Education. 3(17). https://doi.org/10.1115/detc2015-47388

[19] Gökbulut, Y. \& Yücel Yumuşak, E. (2014). The effects of game-supported mathematics learning unit of fractions of 4. grade achievement and permanence. Turkish Studies. 9(2), 673-689.

[20] Guba, E. G. \& Lincoln, Y. S. (1989). Fourth generation evaluation. Newbury Park, CA: Sage.

[21] Hansen, A. (2014). Children's errors in mathematics. London: Sage Publications.

[22] Haser, Ç. \& Ubuz, B. (2003). Students' conception of fractions: A study of 5th grade students, Hacettepe University Journal of the Faculty of Education. 24: 64-69.

[23] Johnson, D. \& Wiles, J. (2003). Effective affective user interface design in games. Ergonomics, 46(13/14), 1332-1345. https://doi.org/10.1080/00140130310001610865

[24] Lau, K. W. \& Lee, P. Y. (2015). The use of virtual reality for creating unusual environmental stimulation to motivate students to explore creative ideas. Interactive Learning Environments, 23(1), 3-18. https://doi.org/10.1080/10494820.2012.745426

[25] Lazzaro, N. \& Keeker, K. (2004). What's my method? A game show on games. In Extended Abstracts of the 2004 Conference on Human Factors in Computing Systems. ACM Press, New York, 1093-1094. https://doi.org/10.1145/985921.985922

[26] Merchant, Z., Goetz, E. T., Cifuentes, L., Keeney-Kennicutt, W. \& Davis, T. J. (2014). Effectiveness of virtual reality-based instruction on students' learning outcomes in K-12 and higher education: A meta-analysis. Computers \& Education. 70, 29-40. https://doi.org/10. 1016/j.compedu.2013.07.033

[27] Orhun, N. (2007). A cognitive gap between formal arithmetic and visual representation in fractional operations. Inonu University Journal of the Faculty of Education. 8(14), 99-111.

[28] Önal, H. \& Yorulmaz, A. (2017). The errors made by primary school fourth graders on fractions. Journal of Research in Education and Society. 4(1), 98-113. 
[29] Pesen, C. (2008). Students' learning difficulties and misconceptions in pointing the fractions on the number line. Inonu University Journal of the Faculty of Education. 9(15), 157168.

[30] Schank, R, C., Fano, A., Bell, B., \& Jona, M. (1993). The design of goal-based scenario. The Journal of Learning Sciences. 3(4), 305-345.

[31] Sherman, H. J., Richardson, L. I. \& Yard, G. (2005). Teaching children who struggle with Mathematics: A systematic approach to diagnosis and instruction, Pearson Education Inc.

[32] Şiap, İ. \& Duru, A. (2004). The ability to use geometrical models in fractions. Gazi University Kastamonu Education Journal, 12(1), 89-96.

[33] Tan S. \& Waugh R. (2013) Use of virtual-reality in teaching and learning molecular biology. In: Cai Y. (eds) 3D Immersive and Interactive Learning. Springer, Singapore. https://doi.org/10.1007/978-981-4021-90-6_2

[34] Taradi, S. K., Taradi, M., Radic, K., \& Pokrajac, N. (2005). Blending problem-based learning with Web technology positively impacts student learning outcomes in acid-base physiology. Advances in Physiology Education, 29(1), 35-39. https://doi.org/10.1152/advan. $\underline{00026.2004}$

[35] Elmqaddem, N. (2019). Augmented Reality and Virtual Reality in Education. Myth or Reality? International Journal of Emerging Technologies in Learning, 14(3), 234-242. https://doi.org/10.3991/ijet.v14i03.9289

[36] Wang, F. (2018). Computer Distance Virtual Experiment Teaching Application Based on Virtual Reality Technology. International Journal of Emerging Technologies in Learning, 13(4), 83-94. https://doi.org/10.3991/ijet.v13i04.8472

[37] Bian, H. (2016). Application of Virtual Reality in Music Teaching System. International Journal of Emerging Technologies in Learning, 11(11), 21-25.

\section{Authors}

Emrah Akman is a PhD student in Primary School Education at Amasya University, Turkey. His interests are virtual reality and developing educational games.

ORCID: http://orcid.org/0000-0003-0637-919X

Recep Çakır is an Assoc. Prof. Dr. in Computer Education and Instructional Technology Department at Amasya University, Turkey. His research focused on information technologies in education, multimedia design and pre and in-service teacher technology training. He has published articles addressing different issues in information technologies and presented papers at several conferences.

ORCID: http://orcid.org/0000-0002-2641-5007

This article has been produced from the doctoral dissertation titled "Developing and Evaluating Virtual Reality Applications About Fractions" that has been conducted by Emrah Akman in company with Recep Çakır's academic advisor.

Article submitted 2019-03-31. Resubmitted 2019-06-08. Final acceptance 2019-06-11. Final version published as submitted by the authors. 